\title{
Estudo de parâmetros de compactação de solo para uso em pavimentos rodoviários
}

\author{
Albaniza Maria Da Silva ${ }^{1}$, Leda Christiane de Figueiredo Lopes Lucena ${ }^{2}$, Adriano Elísio de Figueiredo Lopes \\ Lucena $^{3}$, José Camapum De Carvalho ${ }^{4}$ e Paulo Germano Tavares Marinho Filho ${ }^{5}$
}

\begin{abstract}
Resumo: O processo de compactação desenvolvido por Proctor é o mais difundido atualmente. A NBR 7182/86, que regulamenta este ensaio no Brasil, permite quatro metodologias para execução deste, onde cada uma proporciona distintas estruturas e porosidade dos solos. Este fato pode influenciar no comportamento mecânico e hidraúlico do solo, principalmente em camadas de pavimentos rodoviários que sofrem à influência de alterações ambientais e provocam variações de umidade nas camadas de base e sub-base. Este trabalho teve como objetivo avaliar influência das diferentes metodologias de execução do ensaio Proctor no comportamento mecânico de solos para uso em pavimentos rodoviários. A fase experimental compreendeu ensaios de compactação, compressão simples, resistência à tração por compressão indireta e determinação da curva característica por meio da técnica do papel filtro. Por meio destes ensaios pretendeu-se estabelecer correlações entre as umidades do solo, sucção e resistência mecânica destes. Os resultados demonstraram que as variações na umidade e no método de compactação induzem a um comportamento mecânico diferenciado e que este pode ser compreendido por meio da relação entre a sucção e o teor de umidade.
\end{abstract}

Palavras-chave: sucção, curva característica de sucção, compactação.

\begin{abstract}
The compaction method developed by Proctor is the most used in the world today. The standard NBR $7182 / 86$ (ABNT, 1986), which regulates this test in Brazil, allows four different test methodologies where each provides different structures and porosity of soils. This fact may influence the mechanical and hydraulic behavior of soils, mainly in road pavement layers that under environmental changes, which cause moisture variations in base and sub-base layers. This work aimed to evaluate the influence of the different Proctor test methodologies in the mechanical behavior of soils used in road pavements. The experimental part consisted in the compaction of soil samples, unconfined compression test, tensile strength by diametral compression and the filter paper method to determine the soil water retention curve. From these tests, it was intended to establish correlations between moisture, suction and mechanical strength of the soil. The results demonstrated that variations in moisture and compaction method induce different mechanical behaviors, which could be understood by the relation between suction and water content.
\end{abstract}

Keywords: suction, characteristic curve of suction, compression.

\section{INTRODUÇÃO}

A compactação consiste na redução do índice de vazios do solo, por meio da ação de uma força mecânica auxiliada pela lubrificação das partículas proporcionada pela adição de água que diminui o atrito entre partículas. Este procedimento gera deformações contínuas que modificam a estrutura do solo. O processo de compactação é utilizado com o intuito de melhorar o comportamento hidromecânico do solo (Sivrikaya et al., 2013) e de evitar problemas, como recalques excessivos em rodovias e aterros. O ensaio de compactação mais utilizado, em laboratório, estabelece que a massa específica do solo é função do teor de umidade e da energia de compactação. A padronização Brasileira para este ensaio está preconizada nas seguintes Normas Técnicas NBR 7182/86, DNIT - ME 162/94 e DNIT - ME 164/13.

\footnotetext{
1 Albaniza Maria Da Silva, Departamento de Engenharia Civil, UFCG. (albaniza.engcivil@gmail.com)

2 Leda Christiane de Figueiredo Lopes Lucena, Departamento de

Engenharia, UFCG. (ledach@uol.com.br)

${ }^{3}$ Adriano Elísio de Figueiredo Lopes Lucena ${ }^{3}$, Departamento de

Engenharia, UFCG. (lucenafb@uol.com.br)

4 José Camapum De Carvalho, Departamento de Engenharia, UnB. (camapum@unb.br)

4 Paulo Germano Tavares Marinho Filho, Departamento de Engenharia Civil, UFCG. (marinho.paulo05@gmail.com)
}

Manuscrito recebido em 22/03/2016 e aprovado para publicação em 25/08/2016

Este artigo é parte de TRANSPORTES v. 24, n. 4, 2016. ISSN: 2237-1346 (online). DOI:10.14295/transportes.v24I4.1098
A norma da NBR 7182/86 permite que o ensaio seja realizado por quatro processos distintos: compactação manual com reuso de material, compactação manual sem reuso de material, compactação mecânica com reuso de material e compactação manual sem reuso de material com 24 horas de umedecimento prévio. Estes processos irão conduzir a estruturas, porosidades e distribuições granulométricas dos solos distintas, afetando o comportamento hidráulico e mecânicos destes.

Os pavimentos asfálticos são compostos por camadas de revestimento e camadas granulares (base, sub-base e subleito). As camadas granulares situam-se acima do nível do lençol freático, assim como a maioria das estruturas projetadas em engenharia com solos compactados, apresentando comportamento de solos não saturados (Fredlund e Rahardjo, 1993). O efeito das variações ambientais na umidade do solo pode ser quantificado pelo parâmetro denominado sucção do solo ou por meio da relação entre teor de umidade e sucção (curva característica). Portanto, uma vez que os diferentes métodos de compactação Proctor originam diferentes índices de vazios e estruturas, estes irão responder de modo diferenciado à presença da umidade no solo e consequentemente gerando diferentes sucções que contribuem para o aumento da resistência de solos (Tan Yun-Zhi et al., 2005). Segundo Hanks e Ashoroft (1980) a sucção do solo do pavimento em estado seco pode alcançar valores da ordem de $185 \mathrm{kPa}$. 
SILVA, A.M.; LUCENA, L.C.F.L.; LUCENA, A.E.F.L.; CARVALHO, J.C.; MARINHO, P.G.T.F.

Tabela 1. Caracterização do solo

\begin{tabular}{cccccc}
\hline Propriedades físicas & $\%$ & Granulometria & $\%$ & Análise química & $\%$ \\
\hline Limite de liquidez & $22,4(\%)$ & Pedregulho $(\# 60,00 \mathrm{~mm})$ & 10 & Sílica (SiO2) & $61,72 \%$ \\
Limite de plasticidade & $\mathrm{NP}$ & Areia $(\# 2,00 \mathrm{~mm})$ & 22 & Alumina (Al2O3) & $18,39 \%$ \\
Índice de plasticidade & $\mathrm{NP}$ & Silte $(\# 0,42 \mathrm{~mm})$ & 56 & Óxido de ferro (Fe2O3) & $7,70 \%$ \\
Massa específica & $2,72\left(\mathrm{~g} / \mathrm{cm}^{3}\right)$ & Argila $(\# 0,075 \mathrm{~mm})$ & 12 & Outros óxidos $(\%)$ & $0,98 \%$ \\
& & & & Perda ao fogo (\%) & $0,26 \%$ \\
\hline
\end{tabular}

De acordo com Badillo \& Rodrigues (1976) dentre os fatores que influenciam a compactação obtida os mais importantes são a umidade e energia de compactação e entre os que influenciam a sucção nos solos pode-se citar a granulometria, a composição químico-mineralógica, trajetória de umedecimento e secagem na curva característica (Neto e Carvalho, 1995; Rodrigues, 1997). Alguns estudos (VANAPALLI et al., 1999; SIMMS e YANFUL, 2000; LU e LIKOS, 2004; YANG et al., 2005; LIANG e RABAB'AH, 2007) verificaram a influência da umidade e do arranjo do esqueleto dos solo no comportamento mecânico de solos que compõem pavimentos.

Destaca-se que embora a sucção seja o termo geral normalmente adotado, os mecanismos de atuação no solo variam segundo sua natureza. Nos solos granulares geralmente atua o mecanismo capilar, ou seja, a energia que faz o elo entre partículas é fruto dos meniscos que se formam entre eles. Nos solos finos, particularmente os argilosos, o mecanismo de junção entre as partículas se deve à energia adsorsiva. Embora o termo geralmente adotado seja a sucção, a distinção é importante, pois enquanto na capilaridade predomina o aspecto físico (tamanhos dos poros), na sucção predomina o aspecto químico-mineralógico. Apesar dessa distinção se adotará nesse artigo o termo geral sucção.

Nesse sentido, a literatura mostra que a manifestação física da sucção se dá na forma de uma pressão negativa na água que cria uma forte ligação entre as partículas de solo aumentando sua resistência ao cisalhamento e a rigidez da estrutura (Mullins, 1990; McKyes et al. 1994; Marinho, 1997; Nogueira, 2005; Delgado, 2007). No entanto, faz-se necessário entender que quando o mecanismo é o capilar, essa energia, ao aumentar a tensão nos contatos, amplia a resistência e rigidez dos materiais. Quando o mecanismo é a ampliação da energia adsorsiva a componente que gera a melhoria do comportamento mecânico é de natureza coesiva.

Os projetos geotécnicos de estabilização dos solos, geralmente, não consideram os estudos das estruturas, atribuindo ganho de resistência pela utilização dos aditivos, quando, na verdade, este pode ser consequência da influência da sucção no solo. No Brasil, estudos sobre o comportamento mecânico dos solos relacionados com as variações de teor de umidade ainda são escassos, portanto este trabalho teve por objetivo verificar a influência dos métodos de compactação e da umidade no comportamento mecânico dos solos considerando a influência da sucção.

\section{METODOLOGIA}

\subsection{Caracterização de materiais}

O solo estudado foi fornecido pela empresa ATECEL, proveniente de uma jazida próxima ao sítio Lucas, distrito de Catolé de Boa Vista na cidade de Campina Grande-PB. A Tabela 1 apresenta as características do solo estudado: granulometria, massa específica, limites de Atterberg e análise química do solo.

O solo foi classificado segundo a classificação da AASHTO (American Association of State Highway and Transportation Officials) como areia fina com silte não plástico (A-2-4) e pela metodologia SUCS (Sistema Unificado de Classificação de Solos) como areia siltosa (SM). Observando os resultados da análise química (EDX), podese perceber pouca presença de matéria orgânica, representada pela perda ao fogo, além disso, as amostras eram compostas principalmente de sílica e alumina. O solo apresenta baixa fração de argila, sendo esta considerada inativa, portanto creditando o comportamento dos solos a presença de sílica e quartzo.

\subsection{Compactação}

Neste estudo foram realizados quatro tipos de ensaios de compactação - compactação manual com reuso de material, compactação manual sem reuso de material, compactação mecânica com reuso de material e compactação manual sem reuso de material com 24 horas de umedecimento prévio, nas três energias: normal, intermediária e modificada. Nos quatro casos o solo tinha sido previamente seco ao ar. Todos os tipos de compactação realizados estão de acordo com a metodologia Proctor e seguem as recomendações das normas: NBR - 7182/1986, DNIT - ME 162/1994 e DNIT - ME 164/2013.

A compactação Proctor manual sem reuso foi executada mantendo-se o material por 24 horas na umidade de compactação e seguiu a mesma metodologia anterior em que a compactação era feita imediatamente após o umedecimento do solo. A compactação Proctor mecânica com reuso de material seguiu o procedimento análogo à compactação manual com reuso, entretanto utilizou-se um processo mecânico por meio de um compactador mecânico (Equipamento da Solotest - modelo CN-4230) cujo pistão apresenta forma de 1/8 de círculo com golpes distribuídos no sentido horário.

\subsection{Curva característica de retenção de água}

Para análise dos valores de sucção e sua influência na resistência mecânica à compressão simples, os ensaios de compactação Proctor foram executados na energia Intermediária e extrapolados para as demais energias. A metodologia adotada nesta pesquisa, para o estudo da sucção deu-se por meio da determinação da curva característica do solo pelo método do Papel Filtro foi a seguinte:

a) Foram moldados cinco corpos de prova na prensa Marshall, na energia intermediária para cada uma das compactações Proctor utilizadas na pesquisa. Utilizou-se como referência as umidades ótimas obtidas nos ensaios de compactação e preparou-se amostras na Wót $-6 \%$, Wót $-3 \%$, Wót, Wót + $3 \%$, Wót $+6 \%$; 
b) Os corpos de prova possuíam $2 \mathrm{~cm}$ de altura e $7 \mathrm{~cm}$ de diâmetro. Determinou-se o peso bruto úmido de cada corpo de prova;

c) Cada corpo de prova recebeu Papel Filtro (Whatman $\mathrm{N}^{\circ}$ 42), colocado cuidadosamente, em cada uma de suas faces. Em seguida o conjunto solo-papel filtro foi envolvido com duas camadas de filme de PVC e uma camada de papel alumínio para evitar perda de umidade e permaneceram sete dias em repouso no interior de uma caixa de isopor;

d) Os papéis filtro foram pesados numa balança de precisão de $1.10^{-4}$ gramas e em seguida colocados em cápsulas e secos em estufa por 48 horas, período após o qual foram novamente pesados possibilitando assim a determinação da umidade;

e) Com a umidade do papel e as equações de calibração propostas por Chandler et al. (1992), obteve-se a sucção para o papel filtro utilizado;

f) Sendo as curvas características de retenção de água função, dentre outros, da porosidade do solo, e como foram determinadas para cada técnica de compactação sucções para diferentes porosidades e umidades, recorreu-se utilizando-se os resultados experimentais à metodologia de transformação da curva característica proposta por Camapum de Carvalho e Leroueil (2004) para a determinação das curvas características dos solos compactados.

\subsection{Compressão simples}

O ensaio utilizado para avaliar o comportamento mecânico e a influência da umidade do solo foi o de resistência à compressão simples. Nesse tipo de ensaio alterações na forma da curva apontam para modificações estruturais $(\mathrm{Ca}-$ mapum de Carvalho et al. 1987). Este ensaio é normatizado pela ABNT - NBR 12025/1990. Para realização do ensaio foram moldados corpos de prova para cada condição do ensaio (manual sem reuso, manual com reuso, manual com reuso 24 horas e compactação mecânica) com energia intermediária de compactação. As umidades de moldagem foram obtidas a partir do ensaio de compactação. Após moldagem os corpos de prova foram submetidos à cura ao ar por 7 dias. A prensa utilizada para o rompimento dos corpos de prova foi a SHIMADZU AG-IS com célula de carga de $100 \mathrm{kN}$, velocidade de $1 \mathrm{~mm} / \mathrm{min}$, que permite o traçado simultâneo da curva de resistência conforme execução do ensaio. Adotou-se como critério de parada do ensaio a perda de dez por cento da tensão máxima suportada pelo corpo de prova.

\section{RESULTADOS E DISCUSSÕES}

A Tabela 2 apresenta as umidades ótimas obtidas por meio da compactação para as diferentes técnicas adotadas considerando-se as três energias: Proctor normal, intermediário e modificado. De acordo com Carvalho et al. (1987) solos nos quais a fração areia predomina sobre a argila não são normalmente muito sensíveis, para a variável massa específica aparente seca, à modificação da umidade na compactação. Ainda segundo os autores, no ramo seco da curva de compactação, à medida que se aumenta a saturação irá ocorrer o aumento da massa específica aparente até atingir seu valor máximo na umidade ótima. Esse aumento ocorre por três motivos: maior lubrificação entre os grãos; diminuição da sucção/capilaridade atuando entre os grãos diminuindo a resistência do solo e facilitando a sua compactação; e com o aumento da umidade, ao diminuir a resistência do solo nos contatos entre os agregados, permite que maior energia chegue a contatos entre microagregados até então preservados, possibilitando sua quebra. A umidade ótima é atingida quando ocorre a oclusão da fase ar, momento em que parte da energia total aplicada passa a atuar na fase água gerando pressão neutra positiva e diminuindo a energia efetiva de compactação. A partir deste ponto, quanto maior a umidade, menor será a energia efetiva.

\subsection{Curva característica de sucção}

A Figura 1 apresenta os resultados obtidos para a sucção em função da umidade de compactação considerandose as diferentes técnicas de compactação adotadas, ou seja, embora nessa figura se apresente a relação entre a sucção e a umidade presente no solo, os resultados não correspondem às curvas características propriamente ditas.

Portanto, os pontos que estão formando tendências de curvas na Figura 1 não integram uma única curva característica, mas sim cinco, ou seja, cada ponto refere-se a uma curva característica distinta, embora essas curvas possam ser próximas ou até mesmo coincidentes. Isto ocorreu devido a elas terem sido compactadas em umidades pré-determinadas ao invés de passar por ciclos de umedecimento e/ou secagem. Nas condições específicas de compactação adotadas são gerados índices de vazios, porosidades e eventualmente estruturas distintas, não sendo, portanto, possível definir de modo direto as curvas características do solo.

Segundo Camapum de Carvalho \& Leroueil (2004) um solo ao ser solicitado tem o seu índice de vazios reduzido, mudando assim a curva característica. Isto devido a sucção ser função da umidade, mas também da porosidade e sendo assim, mantida a umidade muda-se a sucção ao se alterar o índice de vazios do solo. No entanto, para um índice de vazios específico tem-se uma curva característica única representativa do material, a não ser que outros fatores, como a distribuição de poros, intervenham.

Tabela 2. Resultados comparativos dos parâmetros ótimos das curvas de compactação

\begin{tabular}{|c|c|c|c|c|}
\hline & & Normal & Intermediário & Modificado \\
\hline Proctor mecânico & Hót $(\%)$ & 11,96 & 10,87 & 9,67 \\
\hline Proctor manual c/ reuso & Hót $(\%)$ & 10,74 & 10,73 & 9,34 \\
\hline Proctor manual s/ reuso & $\mathrm{H}_{o t}(\%)$ & 11,86 & 10,20 & 9,04 \\
\hline Proctor manual s/ reuso $24 \mathrm{~h}$ & $\mathrm{H}_{\mathrm{ot}}(\%)$ & 11,67 & 10,27 & 9,04 \\
\hline
\end{tabular}




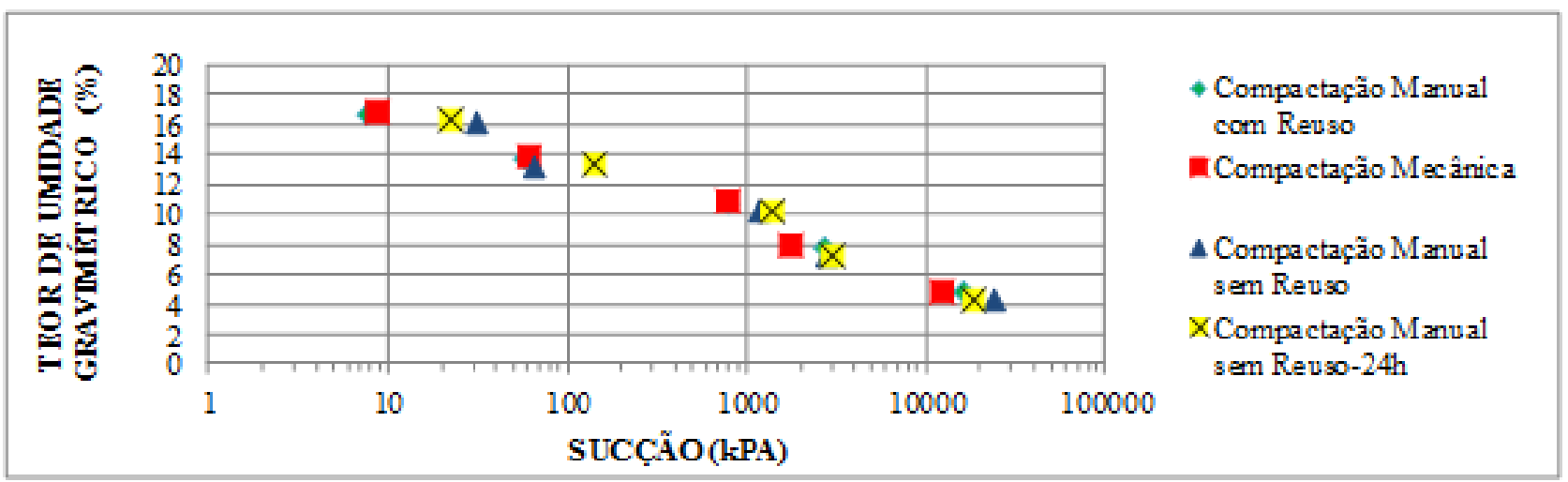

Figura 1. Resultados experimentais de sucção matricial $x$ teor de umidade gravimétrica

Sendo assim, a transformação da curva característica é realizada multiplicando-se a sucção $(\mathrm{pF})$ pelo índice de vazios (e), este produto gera uma curva característica única, representativa de diferentes índices de vazios para a mesma distribuição de poros.

Desta forma, o modelo de transformação da curva característica de retenção de água, sugerido por Camapum de Carvalho \& Leroueil (2004), mostra-se do ponto de vista prático, de grande relevância, tendo em vista que a partir de uma única curva característica de sucção é possível determinar a sucção do solo para índices de vazios diferentes, sem a necessidade de realização de medidas ou acompanhamentos das variações de sucção no solo para novas condições de índice de vazios. Ou seja, curvas de um mesmo material originalmente distintas, em função dos índices de vazios diferentes, assumem uma única tendência sendo esse princípio usado na análise dos resultados obtidos nesse es- tudo. A técnica é particularmente útil na análise dos resultados de ensaios para estudo do comportamento mecânico realizados sobre solos não saturados sem controle de sucção.

O solo utilizado na pesquisa aparentemente não apresentou alteração significativa da distribuição de poros com a energia e umidade de compactação, pois considerando os resultados dos pontos lançados no gráfico e.pF $\times \mathrm{Sr}$, estes aproximam-se de uma única tendência, permitindo assim recuperar as curvas características de cada ponto. Logo, o uso da curva característica transformada (e.pF) permitiu, de modo aproximado, chegar às curvas características do solo para diferentes índices de vazios e para os diferentes procedimentos de compactação utilizados. A Figura 2 apresenta as curvas características transformadas individuais para os quatro processos de compactação Proctor utilizados, na energia intermediária, na função logarítmica.

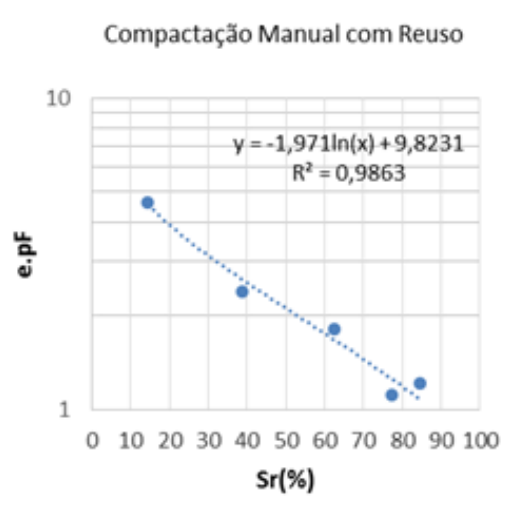

(a) Compactação manual com reuso

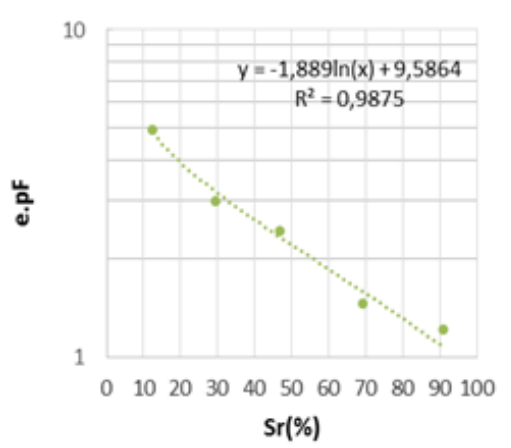

(c) Compactação manual sem reuso

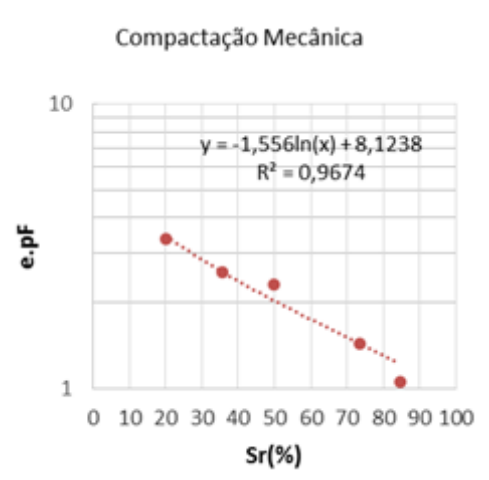

(b) Compactação mecânica

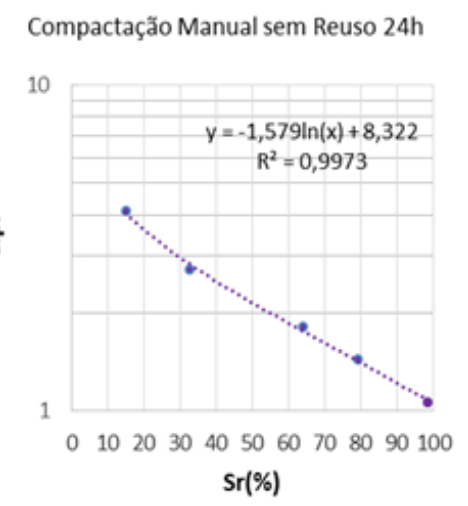

(d) Compactação manual sem reuso $24 \mathrm{~h}$

Figura 2. Curvas características transformadas (e.pF), na energia intermediária 


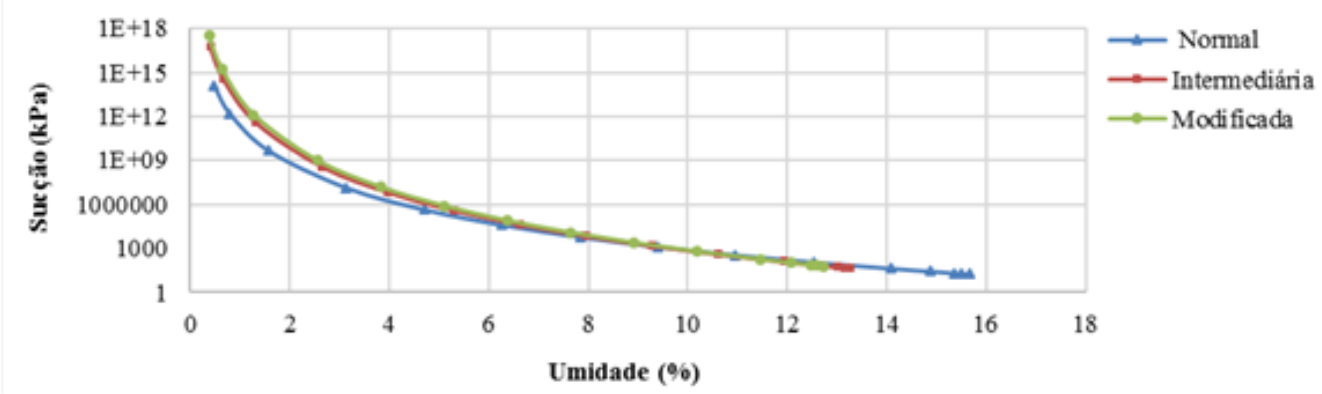

Figura 3. Curvas características da compactação mecânica obtidas por meio de extrapolação: sucção x umidade

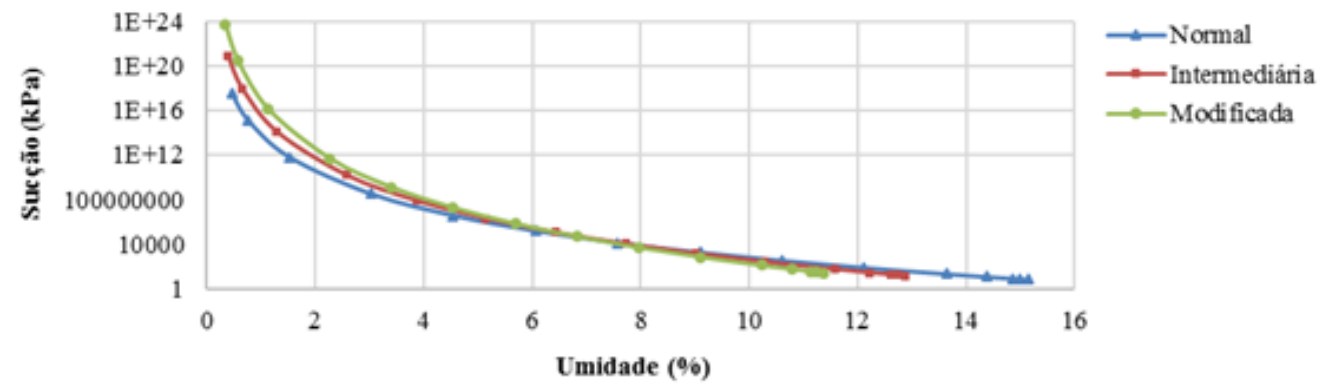

Figura 4. Curvas características da compactação manual com reuso obtidas por meio de extrapolação: sucção $\times$ umidade

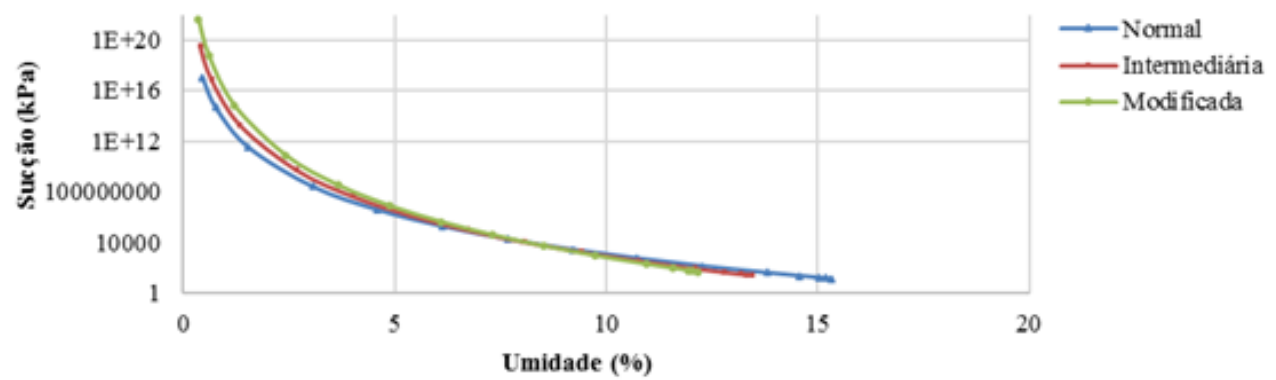

Figura 5. Curvas características da compactação manual sem reuso obtidas por meio de extrapolação: sucção $\times$ umidade

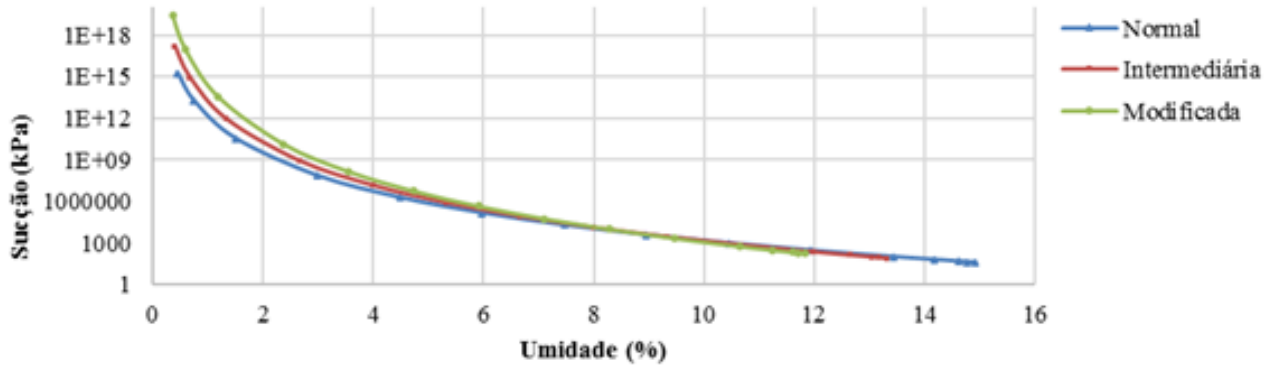

Figura 6. Curvas características da compactação manual sem reuso $24 \mathrm{~h}$ obtidas por meio de extrapolação: sucção $\times$ umidade

Verifica-se por meios das correlações que os coeficientes de determinação de ajuste estatístico $\mathrm{R}^{2}$ foram satisfatórios, pois foram obtidos valores próximos de 1 .

Da mesma forma que existem diferenças nas curvas características geradas a partir dos diferentes processos de compactação Proctor, provavelmente também existirá entre as energias, devido a maior ou menor quebra de partículas e eventuais alterações estruturais. Embora não haja diferenças significativas na distribuição dos poros, a imposição de níveis de quebra ou mesmo materiais ligeiramente distintos entre os processos de compactação utilizados podem ter provocado diferenças nos resultados, dessa forma optou-se por trabalhar com as curvas individualizadas de e.pF $\times \mathrm{Sr}$.

Portanto, a partir das interpolações logarítmicas obtidas para cada um dos processos de compactação, foram encontradas as curvas características próximas do real para cada porosidade dos cinco pontos utilizados anteriormente como se fosse os definidores das curvas características. Por meio da equação de e.pF $\times \mathrm{Sr}$, do respectivo processo de compactação, variando-se o grau de saturação entre $3 \%$ e 98\% e conhecendo-se o índice de vazios de cada energia de compactação correspondente a massa específica aparente seca máxima obtida em cada energia, foram obtidas as curvas características para cada um dos cinco pontos obtidos inicialmente para as energias normal, intermediária e modificada. Ressalta-se que as curvas para a energia normal e modificada foram obtidas por extrapolação a partir das interpolações logarítmicas (Figuras 3 e 6).

Analisando-se as Figuras 3 a 6, observa-se que as curvas características possuem um primeiro trecho onde se observa grande variação de sucção com pequena variação de umidade, seguida de um segundo trecho, onde ocorre menor 
variação de sucção com elevada variação de umidade. Observando as curvas características obtidas nas Figuras 3 a 6 percebe-se uma mesma tendência de comportamento das curvas características. Pode-se observar que quanto menor o teor de umidade gravimétrico maior é a sucção no solo para as 4 compactações utilizadas. Observa-se também que com o aumento da energia de compactação houve um acréscimo nos valores de sucção. Segundo o autor sob elevados valores de sucção $(20000 \mathrm{kPa}$ a $1000000 \mathrm{kPa})$, onde tem-se menores teores de umidade, as curvas características aparentam ser aproximadamente a mesma independentemente do tipo de compactação adotada. Isto indica que para altos valores de sucção a estrutura do solo não tem influência significativa sobre o comportamento da curva característica.

Os ensaios de sucção pelo método do papel filtro foram realizados nas umidades (Hót $\pm 6 \%$ e Hót $\pm 3 \%$ ). Mas, analisando os pontos de umidades (Hót - 1\% e Hót - 2\%), que foram os pontos utilizados nos ensaios mecânicos e que ofereceram significativa influência da sucção para os quatro tipos de compactação, observa-se que apesar das curvas tenderem a apresentar comportamentos similares, verifica-se de um modo geral maiores valores de sucção para as compactações sem reuso de material, este fato pode ser explicado devido à estrutura formada pelos diferentes tipos de compactação. Provavelmente, a estrutura obtida na compactação manual sem reuso $24 \mathrm{~h}$ foi uma das que ofereceram maior influência nas referidas umidades, pois proporcionou maiores resultados de sucção. A incorporação de água 24 horas antes da compactação pode ter promovido uma maior uniformização da umidade que resultou em mudanças na porosidade.

\subsection{Resistência à compressão simples}

Os ensaios de resistência à compressão simples (RCS) foram executados com a finalidade de se obter a tensão de ruptura de cada corpo de prova para os diferentes ipos de moldagem utilizados na pesquisa. A partir das curvas características de sucção transformadas $(e . p F \times \mathrm{Sr}$ ) foram feitas análises do comportamento mecânico em termos de RCS em função da relação sucção em pF/índice de vazios. Essa análise se fundamenta na proposta apresentada por Camapum de Carvalho et al. (2002) que mostraram que o comportamento mecânico apresenta uma boa relação com pF/e e pF.e. Essa interação depende, respectivamente, se o parâmetro analisado apresenta comportamento inversamente proporcional à variação da porosidade do solo, e.g. coesão, ou se apresenta comportamento diretamente proporcional ao aumento da porosidade, e.g. o coeficiente de colapso.

Para o estudo do comportamento mecânico, conhecendo-se o índice de vazios e a umidade do corpo de prova pós-ruptura, foi obtido o valor do grau de saturação, e com este valor a partir da equação definida pela curva característica transformada foi possível estimar o valor da sucção em pF. Com os valores de sucção em pF, com os valores do índice de vazios, e com os respectivos valores de RCS foram obtidos os gráficos individualizados de comportamento mecânico para o conjunto de pontos de RCS versus $\mathrm{pF} / \mathrm{e}$ para cada processo de compactação utilizado na pesquisa (Figuras 11 a 14).

Verificou-se por meio das Figuras 12 a 14 que houve uma certa dispersão entre os pontos, principalmente nas compactações com reuso, sem reuso e sem reuso $24 \mathrm{~h}$. Em contrapartida analisando a Figura 11 verificou-se uma ótima relação para a compactação mecânica e essa é uma informação relevante, pois reflete o melhor controle e repetitividade na compactação. A Figura 15 apresenta as curvas do comportamento mecânico (RCS) versus $\mathrm{pF} / \mathrm{e}$ para todos os processos Proctor utilizados nos três níveis de energia. Nessa figura optou-se por agregar os pontos como ramo seco, condição ótima e ramo úmido. Observa-se na Figura 15 que a dispersão dos resultados tende a aumentar do ramo úmido para o ramo seco sendo que tal dispersão demonstra a relevância da técnica de compactação, pois as mesmas ao provocarem níveis de quebra de grãos distintos terminam interferindo em características como distribuição dos poros e sucção. Os pontos que tenderam a desviar da tendência foram os últimos do ramo úmido, os quais tem maior umidade.
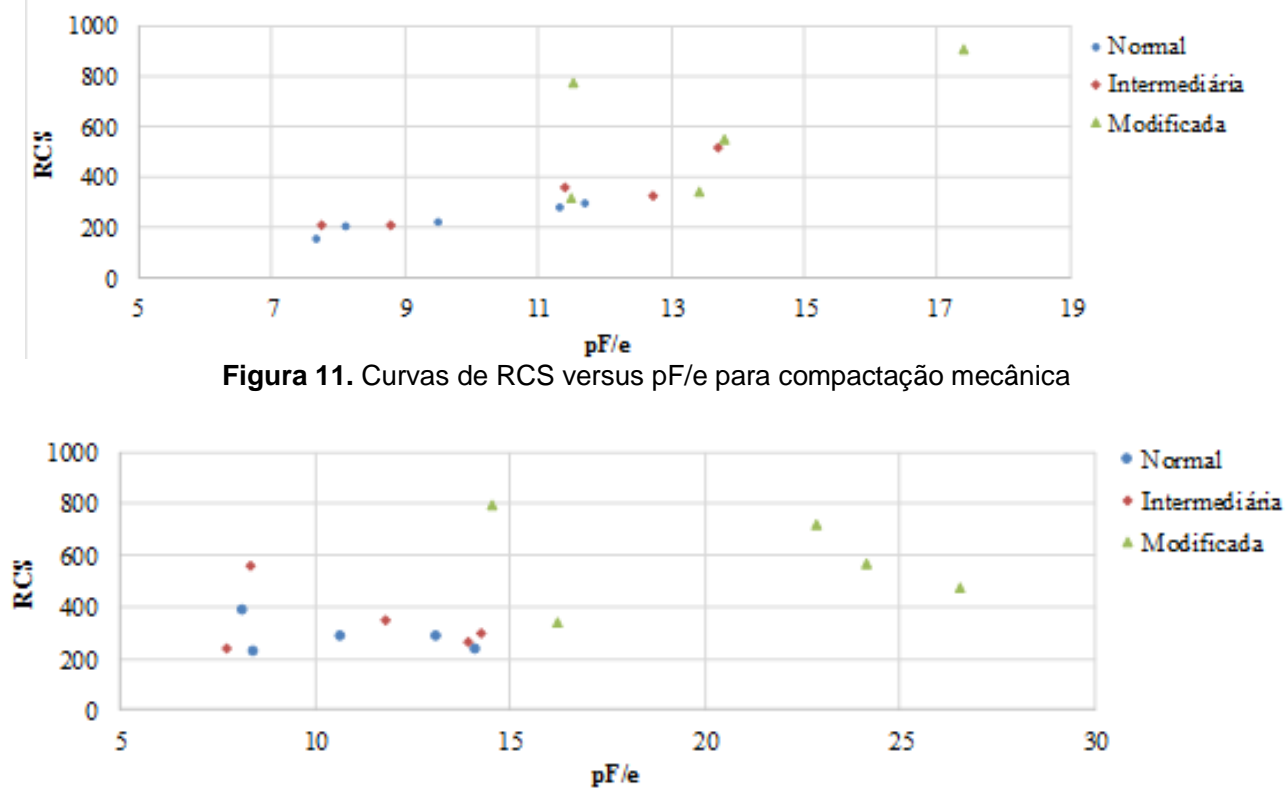

Figura 12. Curvas de RCS versus $\mathrm{pF} / \mathrm{e}$ para compactação manual com reuso 


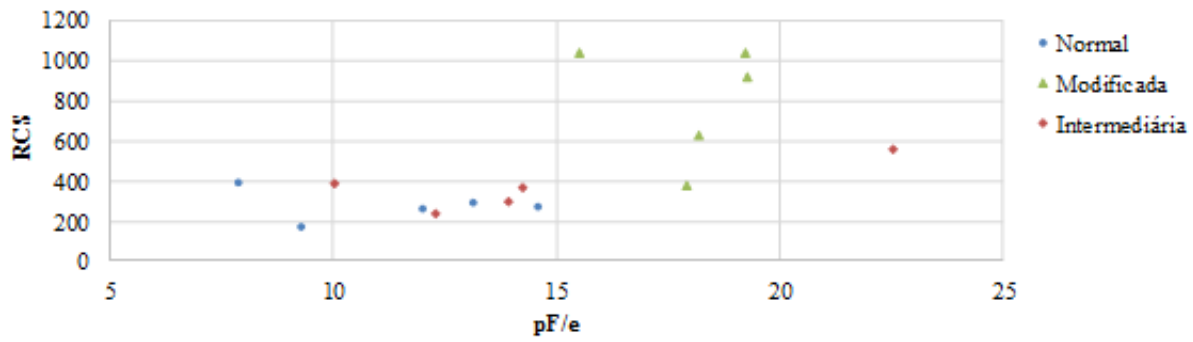

Figura 13. Curvas de RCS versus $p F / e$ para compactação manual sem reuso

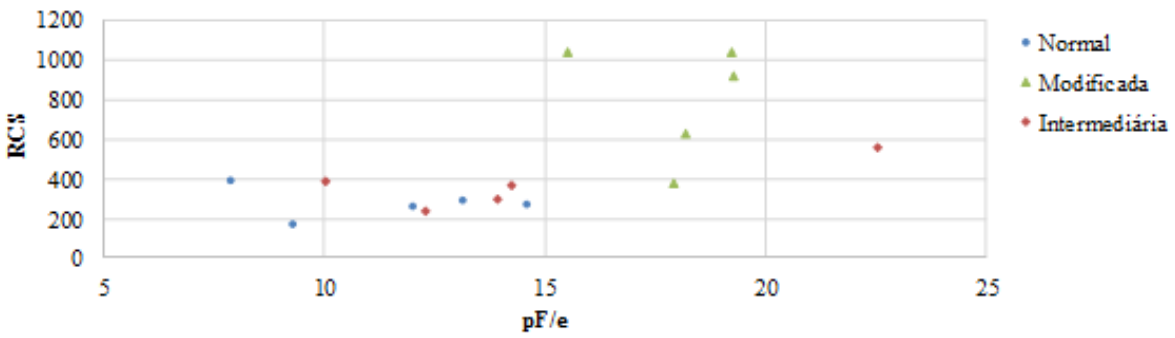

Figura 14. Curvas de RCS versus pF/e para compactação manual sem reuso $24 \mathrm{~h}$

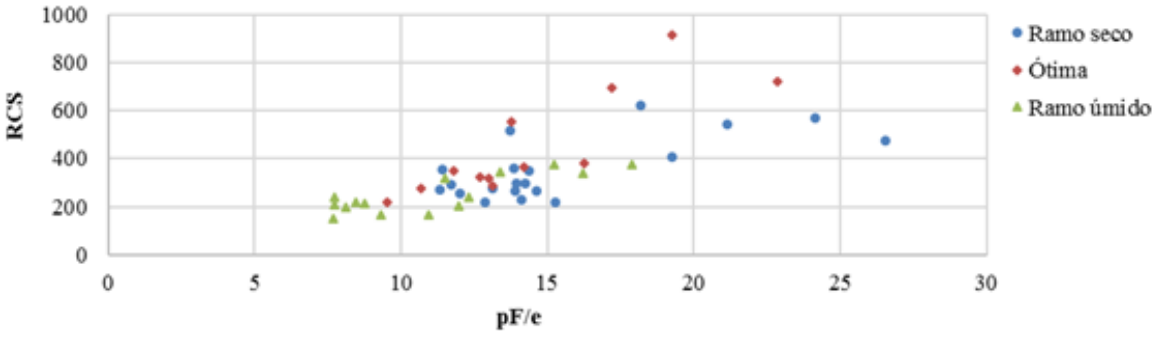

Figura 15. Curvas de RCS versus pF/e para todas as compactações nos três níveis de energia, no ramo seco e úmido

\subsection{Curvas de iso-sucção}

Em análise complementar foram traçadas as curvas de iso-sucção em relação às curvas de compactação. As curvas de iso-sucção são importantes para entender o comportamento do solo e os resultados da compactação. Para o traçado das curvas de iso-sucção foram utilizadas as curvas características estimadas, considerando as curvas características transformadas individuais de todos os processos de compactações Proctor utilizados na pesquisa. As Figuras 16 a 19 apresentam as curvas de iso-sucção do solo estudado para os quatro processos de compactação.

Analisando-se as Figuras 17 a 19 verifica-se, de um modo geral, que as sucções nas umidades ótimas, umidades correspondentes à oclusão da fase ar, aumentam com a energia de compactação. Constata-se ainda, devido à presença de sucções relativamente altas no ramo úmido, que a pressão neutra positiva oriunda da energia do golpe quando a fase ar está oclusa, tende a desaparecer após o golpe dando origem a atuação de uma sucção. Essa observação é particularmente relevante e merece ser melhor estudada a partir de ensaios com maior controle da sucção atuante durante os ensaios, pois se confirmada requer análises mais cuidadosas do comportamento mecânico obtido em ensaios como os de carga repetida. Essa percepção, se confirmada, pode ter grande relevância prática na avaliação do desempenho da estrutura de pavimento em função do nível e frequência das cargas.

\section{CONCLUSÕES}

O Brasil situa-se em uma região onde predomina o clima tropical, portanto ocasionando que os solos existentes nas camadas granulares comportem-se como solos não saturados, por outro lado, as dificuldades construtivas impedem o isolamento da estrutura do pavimento do lençol freático. Os métodos de compactação Proctor resultaram em diferentes distribuições dos vazios, a compressibilidades do solo e estruturas do material. Este estudo mostrou que os fatores supracitados são agentes importantes nas alterações mecânicas dos solos constituintes do pavimento.

Embora possa ocorrer dificuldade de compactação de certos materiais na umidade ótima determinada no ensaio de compactação proctor, embora ainda no limite de tolerância permitido pela norma, a variação de umidade pode ser representativas.

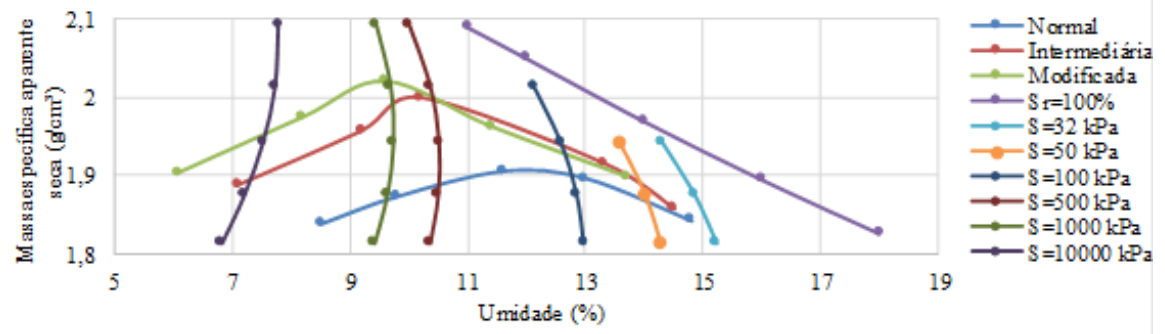

Figura 16. Curvas de iso-sucção do solo estudado para a compactação mecânica 


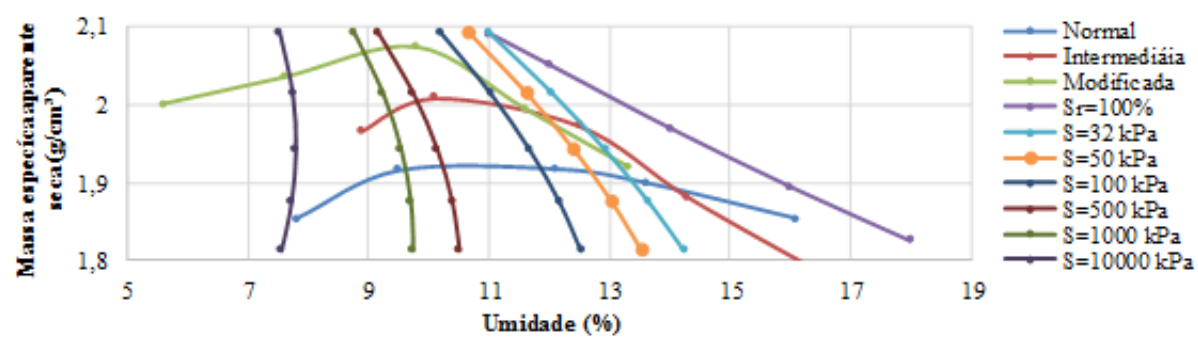

Figura 17. Curvas de iso-sucção do solo estudado para a compactação manual com reuso

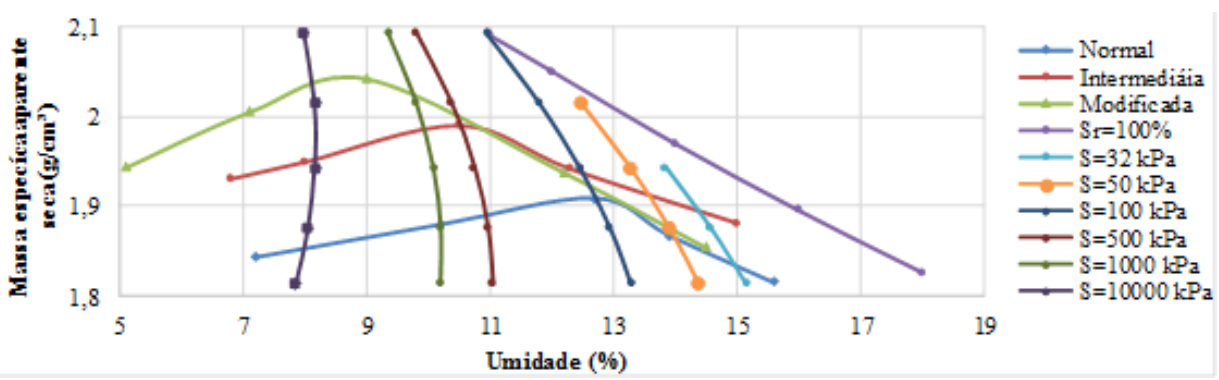

Figura 18. Curvas de iso-sucção do solo estudado para a compactação manual sem reuso

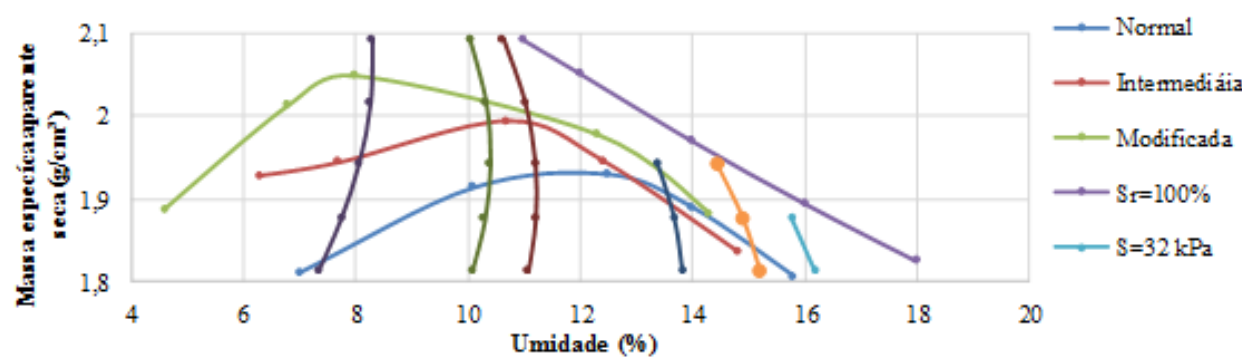

Figura 19. Curvas de iso-sucção do solo estudado para a compactação manual sem reuso $24 \mathrm{~h}$

As amostras moldadas em umidades inferiores à ótima apresentaram melhores resultados mecânicos em razão da ação da sucção. Este fato corrobora a necessidade do controle do teor de umidade na compactação em campo. A umidade irá afetar as propriedades das camadas granulares do pavimento e, consequentemente, a capacidade da estrutura de suportar o carregamento imposto pelo tráfego.

Sugere-se ainda que sejam realizados estudos suplementares avaliando o impacto de procedimentos como a secagem prévia e o destorroamento do solo como preparação de amostras para compactação, pois tais procedimentos podem levar a estimativas errôneas do comportamento in situ de solos em rodovias. Além disso, o estudo dos métodos de compactação, associados a diferentes umidades, e submetidos a carregamentos cíclicos podem ajudar a preencher lacunas existentes neste estudo.

\section{REFERÊNCIAS}

AMERICAN ASSOCIATION OF STATE HIGHWAY AND TRANSPORTATION OFFICIALS. AASHTO (2002). Guide for design of pavement structures. Washington, EUA: American Association of State Highway and Transportation Officials

Badillo, J.; Rodriguez, R. (1976). Mecánica de suelos: fundamentos de la mecânica de suelos. México, $3^{\circ}$ ed, 642 p.

DEPARTAMENTO NACIONAL DE INFRAESTRUTURA DE TRANSPORTES (1994). DNIT - ME 162/94 Solos - ensaio de compactação utilizando amostras trabalhadas. Rio de Janeiro
(2103). DNIT - ME 164/13. Solos - ensaio de compactação utilizando amostras não trabalhadas. Método de ensaio. Rio de Janeiro

Camapum de carvalho, J.; Pereira, J.H.F; Guimarães, F. C. (2002) Courbes de rétention d'eau d'un profil d'altération. In: Third International Conference on Unsaturated Soils - UNSAT 2002 10-13 March,Recife, Brazil.

Camapum de carvalho, J. \& Leroueil, S. (2004). Curva Característica de Sucção Transformada. Solos e Rochas, 27(3): 231-242

Camapum de carvalho, J., Nunes, P.M., Berberian, D. \& Ferreira, E.S. (1987) Influência Del líquido de saturatión em La colapsibidad. VIII Congresso Panamericano de Mecânica dos Solos e Engenhariade Fundações, Cartagena-Colômbia.

Chandler, R. J.; Crilly, M. S.; Montgomery-Smith, G. (1992). A low-Cost method of assessing clay desiccation for low-rise buildings. Proceeding of the Institute of Civil Engineering, $n^{\circ} 2$, pp. 82-89. DOI: 10.1680/icien.1992.18771

Delgado, A. K. C. (2007). Estudo do Comportamento Mecânico de solos tropicais característicos do Distrito Federal para uso na Pavimentação Rodoviária. Tese de Doutorado submetida ao Departamento de Engenharia Civil e Ambiental da Universidade de Brasília.

Fredlund, D. G.; Rahardjo, H (1993). Soil Mechanics for Unsatured Soils. John Wiley \& Sons, New York.

Hanks, R. J.; Ashoroft, G. L (1980). Applied soil physics. Advanced Series in Agricultural Sciencs 8. Springer- Verlag, New York. 
Liang, R.Y., Rabab'ah, S. (2007) Predicting Moisture-dependent Resilient Modulus of Cohesive Soils Using Soil Suction Concept, XIII Conferência Panamericana em Mecânica dos Solos e Engenharia Geotécnica, Venezuela.

Lu, N., LIKos, W.J. (2004) Unsaturated Soil Mechanics, John Wiley \& Sons, Inc.

Marinho, F. A M. (1997). Medidas de sucção em solos. In: Encontro sobre Solos Não Saturados, Rio de Janeiro. III Simpósio Brasileiro de Solos Não Saturados, T. M. P. de Campos \& E. A. Vargas Jr (eds), Freitas Bastos Editora, Rio de Janeiro, v. 2, p 373-397.

Mckyes, E.; Nyamugafata, P.; Nyamapene, K. W. (1994). Characterization of cohesion, friction and sensitivity of two hardsetting soil from Zimbabwe. Soil and Tillage Research 29: 357-366. DOI: 10.1016/0167-1987(94)90108-2

Mullins, C. E.; Macleod, D. A.; Northcote, K. H.; Tisdall, J. M.; Young, I. M. (1990). Hardsetting soils: behavior, occurrence and management. Advances in Soil Science 11: 37-108.

Neto, P. M. S.; Carvalho, J. C. (1995). Métodos para medir a sucção em solos não saturados. Encontro sobre Solos Não Saturados, pp. 143-158. Porto Alegre.

Nogueira, J. F. (2005). Análise da Influência do Fluxo por Capilaridade na degradação físico-quimico do solo. Dissertação de Mestrado em Geotecnia - Universidade de Brasília

Rodrigues, M. R. (1997). Influência da sucção no módulo de resiliência dos solos típicos de subleito de pavimentos do Rio Grande do Sul. Tese de mestrado submetida ao corpo docente do Curso de Pós-Graduação de Engenharia Civil Escola da Universidade Federal do Rio Grande do Sul. Porto Alegre.

Simms, P.H., Yanful, E.K. (2000) Estimation of a Soil-water Characteristic Curve of a Clayey Till Using Measured pore-size Distribution, 5th International Symposium on Environmental Geotechnology and Global Sustainable Development, Belo Horizonte, Brazil.

Sivrikaya, O.; Kayadelen, C.; CECEN. E. (2013). Prediction of the compaction parameters for coarse-grained soils with fines content by mlr and gep. Acta geotechnica slovenica.

Tan, Y.; Wang, S.; Chen, Y. (2005). Soil-water characteristic curve study. The second national symposium on unsaturated soil, Hangzhou: Zhejiang University.

Vanapalli, S.K., Fredlund, D.G., Pufahl, D.E. (1999) The influence of soil structure and stress history on the soil-water characteristics of a compacted till. Géotechnique, 49(2), pp. 143159. DOI: $10.1680 /$ geot.1999.49.2.143

Yang, S.J., Huang, W.H., Tai, Y.T. (2005) Variation of Resilient Modulus with Soil Suction for Compacted Subgrade Soils, 84th TRB Annual Meeting, Washington, D.C. 